\title{
Didier Oriet, La Susanne (1581)
}

\section{Dario Cecchetti}

\section{OpenEdition}

\section{Journals}

\section{Edizione digitale}

URL: https://journals.openedition.org/studifrancesi/3050

DOI: 10.4000/studifrancesi.3050

ISSN: 2421-5856

\section{Editore}

Rosenberg \& Sellier

\section{Edizione cartacea}

Data di pubblicazione: 1 juillet 2013

Paginazione: 443

ISSN: 0039-2944

\section{Notizia bibliografica digitale}

Dario Cecchetti, «Didier Oriet, La Susanne (1587)», Studi Francesi [Online], 170 (LVII | II) | 2013, online dal 30 novembre 2015, consultato il 02 février 2023. URL: http://journals.openedition.org/studifrancesi/ 3050 ; DOI: https://doi.org/10.4000/studifrancesi.3050

\section{Questo documento è stato generato automaticamente il 2 février 2023.}

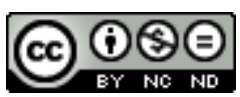

Creative Commons - Attribuzione - Non commerciale - Non opere derivate 4.0 Internazionale - CC BYNC-ND 4.0

https://creativecommons.org/licenses/by-nc-nd/4.0/ 


\title{
Didier Oriet, La Susanne (1581)
}

\author{
Dario Cecchetti
}

\section{NOTIZIA}

DIDIER ORIET, La Susanne (1581), edizione critica a cura di Riccardo BENEDETTINI, Fasano, Schena Editore, 2012, pp. 201.

1 Nell'ambito delle pubblicazioni patrocinate dal «Gruppo di studio sul Cinquecento francese» Riccardo Benedettini offre l'edizione critica di un testo di Didier Oriet, un poeta che risente dell'influsso di Du Bartas, autore di due grandi poemi biblici, $\mathrm{La}$ Susanne (1581) e il Livre de l'Esther (1584), e di una Paraphrasis poetica in lamenta Jeremiae (1586). Si tratta di opere presto dimenticate, ma che presentano un interesse critico indubbio: in particolare in questi ultimi decenni, in cui - lungo la strada aperta dai lavori pionieristici di Terence Cave e Michel Jeanneret che sfocia nelle grandi sistemazioni critiche di Anne Mantero, Michèle Clément, Christophe Bourgeois e Véronique Ferrer - ci si è posto il problema della poesia religiosa come poesia che mutua dalla Bibbia un preciso lessico ed elabora una precisa poetica, sulla base appunto della parafrasi. In questa prospettiva si sono fatti convegni che hanno proposto nuove piste di ricerca. Ricordiamo almeno, per l'elaborazione di una poetica della parafrasi biblica, il convegno di Bordeaux (Les paraphrases bibliques au XVI et XVII siècles, a cura di V. Ferrer e A. Mantero, Genève, Droz, 2006: cfr. questi «Studi», 152, 2007) e, per quanto concerne la reinterpretazione del personaggio biblico a livello letterario (il che comporta evidentemente anche problematiche di linguaggio), il convegno di Verona (Le donne della Bibbia, la Bibbia delle donne. Teatro, letteratura e vita, a cura di R. Gorris Camos, Fasano, Schena Editore, 2012: cfr. questi «Studi», 169, 2012). R. Benedettini, editando il lungo poema di Oriet (la Susanne supera i 4000 versi), apporta materiale utile per ricerche che vanno nella duplice direzione segnata da questi convegni. Nella Presentazione (pp. 7-41), infatti, non solo sottolinea i rapporti del testo di Oriet con le versioni bibliche e le peculiarità del dettato cinquecentesco, ma, studiando la configurazione dei personaggi, evidenzia le modalità con cui le tecniche descrittive operano una variatio sull'archetipo scritturale. L'edizione si raccomanda anche per le 
osservazioni sulla lingua di Oriet e per la puntuale raccolta di dati storici. Possiamo, dunque, augurarci che l'A. consacri presto il suo ulteriore impegno all'edizione dell'Esther. 